\title{
Selection criteria using the Delphi method for siting an integrated hazardous waste disposal facility in Malaysia.
}

\begin{abstract}
Choosing the site for an integrated hazardous waste disposal facility requires an extensive evaluation process to identify the best available disposal location. This location must comply with the requirements of governmental regulations while minimising the economic, environmental, health and social costs. In addition, the local public must be convinced that the hazardous waste disposal facility is required and that all reasonable steps will be taken to make it compatible with the environment. In addition, the location of the facility should be able to reasonably resolve larger issues. This study identifies environmental, economic and social criteria to be considered for the site selection of an integrated hazardous waste disposal facility. The Delphi method was employed in this study to gather information on the site selection criteria for siting a fully integrated hazardous waste disposal facility in Malaysia. The use of an online Delphi survey is useful and effective when both time and costs are limitations in a study, due to geographically dispersed experts. A two-round Delphi survey was employed in this study. The overall findings indicate that environmental criteria should be given priority when locating the facility, followed by the social and economic criteria.
\end{abstract}

Keyword: Hazardous waste; Disposal facility; Site selection criteria; Delphi method. 